\title{
Erratum to: Performance of PSI, CURB-65, and SCAP scores in predicting the outcome of patients with community-acquired and healthcare-associated pneumonia
}

Marco Falcone - Salvatore Corrao •

Mario Venditti · Pietro Serra - Giuseppe Licata

Published online: 24 November 2011

(C) SIMI 2011

Erratum to: Intern Emerg Med (2011) 6:431-436

DOI 10.1007/s11739-011-0521-y

In appendix section, a participating member's name was misspelled as Raffaella Rossi. The correct spelling should be Raffaella Rossio.

The online version of the original article can be found under doi:10.1007/s11739-011-0521-y.

M. Falcone $(\varangle) \cdot$ M. Venditti · P. Serra

Department of Public Health and Infectious Diseases, Policlinico

Umberto I, University of Rome "La Sapienza", Rome, Italy

e-mail: marcofalc@libero.it

S. Corrao - G. Licata

Department of Internal Medicine, University of Palermo,

Palermo, Italy 